CONTABILIDADE 


\title{
ESTUDOS NA CONTABILIDADE GERENCIAL: TEMAS, MÉTODOS E TEORIAS
}

\author{
STUDIES IN MANAGEMENT ACCOUNTING: \\ TOPICS, METHODS AND THEORIES
}

Micheli Aparecida Lunardi Correio

Universidade Regional de Blumenau

Alini Da Silva

Universidade Regional de Blumenau

Caroline Sulzbach Pletsch

Universidade Regional de Blumenau
Marcia Zanievicz Silva

Universidade Regional de Blumenau
Data de submissão: 09 abr. 20 | 8. Data de aprovação:

I 5 nov. 20 |8. Sistema de avaliação: Double blind review.

Universidade FUMEC / FACE. Prof. Dr. Henrique Cordeiro

Martins. Prof. Dr. Cid Gonçalves Filho.

\section{RESUMO}

Este estudo teve por objetivo realizar uma pesquisa bibliométrica dos artigos na área de contabilidade gerencial publicados em dez importantes revistas internacionais de contabilidade, no período de $200 \mathrm{I}$ a 2018 . Identificou-se os temas, métodos, teorias, características de autoria e rede social dos autores. Utilizou-se como procedimentos metodológicos aspectos descritivos, bibliométrico e quantitativo. Os resultados demonstraram que os temas mais investigados foram mensuração e avaliação de desempenho e sistema de controle gerencial, constata-se que as pesquisas de assimetria de custos e mudanças na contabilidade gerencial ganharam destaque. Como métodos observou-se levantamento de dados, estudo de caso e experimento. As teorias predominantes são as econômicas, porém podem-se observar pesquisas com cunho psicológico, sociológico e da física. Os autores, em sua maioria, apresentaram um artigo publicado, os que possuem mais de um artigo possuem redes sociais colaborativas pequenas, no entanto, o aumento destas redes colaborativas pode contribuir para o desenvolvimento da contabilidade gerencial.

\section{PALAVRAS-CHAVE}

Contabilidade Gerencial. Principais Revistas Internacionais. Temas. Métodos e Teorias. Redes de autores. 


\section{ABSTRACT}

This study aimed to carry out a bibliometric survey of articles in the area of managerial accounting published in ten major international accounting journals from $200 \mathrm{I}$ to 2018. The authors' themes, methods, theories, authorship characteristics and social network were identified. Descriptive, bibliometric and quantitative aspects were used as methodological procedures. The results showed that the most investigated subjects were measurement and performance evaluation and management control system, it is verified that the asymmetry research of costs and changes in managerial accounting gained prominence. As methods were observed data collection, case study and experiment. The predominant theories are economic, but one can observe psychological, sociological and physical research. The authors, for the most part, presented a published article, those who have more than one article have small collaborative social networks, however, the increase of these collaborative networks can contribute to the development of managerial accounting.

\section{KEYWORDS}

Management accounting. Major International Magazines. Themes. Methods and Theories. Networks of authors.

\section{INTRODUÇÃO}

A contabilidade pode ser estudada sob as mais variadas ênfases teóricas e abordagens, tais como: ética, macroeconomia, Teoria Institucional, abordagem social, comportamental, sistêmica, histórica, entre outras (IUDíCIBUS; MARTINS; CARVALHO, 2005). Dentre as áreas da contabilidade há a contabilidade gerencial, que dispõe de um conjunto de artefatos gerenciais e que, por intermédio de teorias organizacionais fornece um contexto para explicar e compreender os processos gerenciais (ZUCCOLOTTO; SILVA; EMMENDOERFER, 20I0). Ainda, Silva e Beuren (20I5) destacam que a contabilidade gerencial possui, por finalidade, disponibilizar informações para o planejamento e o controle organizacional e assim, apoiar a tomada de decisão dos usuários internos, independentemente do nível hierárquico em que se encontra.
Nas últimas duas décadas, a contabilidade gerencial tem sofrido críticas quanto à validade de suas práticas. Apesar do ambiente mais competitivo e exigente enfrentado pelas empresas, a contabilidade gerencial muitas vezes não consegue se atualizar e adotar práticas capazes de suprir informações adequadas às novas exigências decisórias (SOUZA; LISBOA; ROCHA, 2003). Revoluções na contabilidade gerencial podem ser necessárias para ajudar as empresas a enfrentar os desafios globais nos mercados competitivos (SOUZA; LISBOA; ROCHA, 2003).

As pesquisas em contabilidade gerencial surgem com o intuito de apresentar novas ferramentas para atender as necessidades das práticas das empresas, as quais devem se adaptar, utilizando teorias organizacionais ou sociológicas para examinar o desenvolvimento, manutenção e mudanças 
nas práticas de contabilidade gerencial, contribuindo com sua reformulação e avanço (COVALESKI; DIRSMITH; SAMUEL, 1996). Novas pesquisas em contabilidade gerencial devem proporcionar entendimento entre as relações institucionais, culturais e psicológicas dentro das empresas, e por meio de dados empíricos apresentarem fatores inconscientes que influenciam a estruturação da contabilidade gerencial (GUERREIRO; FREZATTI; CASADO, 2006).

Por conseguinte, a bibliometria, por meio de indicadores, contribui para avaliar a pesquisa acadêmica, além de demonstrar rumos ou tendências de estudos e estratégias para a consecução de pesquisas (LEITE FILHO, 2008). Nesta perspectiva, na contabilidade gerencial, estudos bibliométricos e de revisão surgiram com o intuito de desmistificar o conhecimento sobre a área, demonstrar tendências e contribuir com o seu avanço. Cooper (1983) desenvolveu um estudo com o objetivo de comentar e incentivar a reflexão crítica sobre o estado da pesquisa em contabilidade gerencial, demostrando as direções nas quais as pesquisas pareciam estar se movendo e ilustram possíveis divergências de pesquisa. Brown e Gardner (1985) avaliaram as contribuições de pesquisas publicadas na revista Contabilidade, Organizações e Sociedade (AOS). Examinaram os métodos de pesquisa empregados e as citações, como o objetivo de determinar, especificamente na AOS, o impacto de suas publicações e identificaram os artigos que exerceram maior impacto sobre as ciências sociais.

Kaplan (1986) explorou a legitimidade de estudos empíricos em contabilidade gerencial e explicou o papel que devem desempenhar no desenvolvimento da contabilidade gerencial. Oliveira (2002) analisou as características dos periódicos brasileiros de contabilidade, destacando os temas mais abordados que evidenciaram mudanças no paradigma contábil gerencial. Hesford et al. (2007) analisaram, em um recorte temporal de 20 anos (198I-2000), os tipos de tópicos estudados, os métodos de pesquisa utilizados, e as disciplinas de origem empregados nos estudos de contabilidade gerencial, através da análise de dez revistas em contabilidade. Além disso, observaram as citações e medidas de redes sociais que revelaram as ligações entre os autores e a influência dos indivíduos na pesquisa em contabilidade gerencial.

Observam-se estudos nacionais e internacionais sobre a contabilidade gerencial, que foram realizados e publicados em importantes periódicos mundiais, com a preocupação de analisar as tendências desta área, que ainda se encontra dispersa. Com base nesta problemática de observar padrões nas pesquisas em contabilidade gerencial no mundo e demonstrar tendências nesta área, tem-se como problema de pesquisa: quais são os temas, métodos de pesquisa, teorias organizacionais, demais perspectivas teóricas empregadas, características de autoria e medidas de redes sociais nos estudos de contabilidade gerencial publicadas no período de 2001 a 2018 em dez importantes revistas de contabilidade? A fim da resolução deste problema de pesquisa, tem-se como objetivo realizar um estudo bibliométrico da contabilidade gerencial. A intenção é de observar as alterações em determinados aspectos de estudos da contabilidade gerencial em relação ao estudo de Hesford et al. (2007), pela atualização posteriores de sua pesquisa, apresentando tendências de publicações.

A presente pesquisa teve por justificati- 
va contribuir com evidências adicionais aos estudos mencionados, buscando entender, criar padrões e traçar tendências das pesquisas realizadas em contabilidade gerencial. Também, tem-se como contribuição a análise de período posterior ao estudo realizado por Hesford et al. (2007) - período de 200I a 2018. Destaca-se que o artigo de Hesford et al. (2007) serviu como inspiração para a realização da pesquisa, deste modo, procede-se também a comparação dos resultados do atual estudo com o anterior, evidenciando-se em período mais atual o rumo das pesquisas em contabilidade gerencial sobre os temas de avaliação de desempenho, sistema de controle gerencial e outros, como assimetria de custos. Também, se constatou a retomada de utilização do método experimento. Além disso, são analisadas as redes de autores, características de autoria e investigações sobre contabilidade gerencial constantes em revistas com tendência de publicação na Europa e na América do Norte.

Diante da incipiência de resultados em pesquisas realizadas na contabilidade gerencial, que possam traçar tendências sobre o rumo desta área, o estudo busca contribuir ao demonstrar novas perspectivas de pesquisas empíricas, evidenciando a evolução das pesquisas em contabilidade gerencial nos principais periódicos internacionais após o estudo de Hesford et al. (2007) e apontar possibilidades de estudos futuros pela análise de fragilidades e potencialidades observadas. Ainda, segundo Mcrae (1974) e Murcia e Borba (2008) as revistas de contabilidade gerencial tem a tendência de serem receptivas há diferentes estudos, com o intuito de contribuir com o avanço da ciência, demonstrando também a influência que casos empresariais possuem no conhecimento acadêmico. Por tal motivo, tornam-se relevantes estudos bibliométricos no âmbito da contabilidade gerencial.

\section{PROCEDIMENTOS METODOLÓGICOS}

A presente pesquisa quanto ao objetivo configura-se como descritiva e em relação aos procedimentos como bibliométrica. A população correspondeu a todos os artigos publicados em dez revistas internacionais de contabilidade no período analisado de 200 I a 20I8. Para a classificação dos periódicos utilizou-se o estudo de Hesford et al. (2007) que estabeleceu as seguintes revistas: Accounting, Organizations and Society (AOS); Behavioral Research in Accounting (BRIA); Contemporary Accounting Research (CAR); Journal of Accounting and Economics (JAE); Journal of Accounting Literature (JAL); Journal of Accounting Research (JAR); Journal of Management Accounting Research (JMAR); Management Accounting Research (MAR); Review of Accounting Studies (RAS) e The Accounting Review (TAR).

Dentre estas dez revistas analisadas, duas possuem como foco principal a publicação de artigos de contabilidade gerencial (JMAR e MAR), desta forma, utilizou-se para a análise todos os artigos publicados no período analisado, destas duas revistas. Nas demais revistas mencionadas, utilizou-se para a amostra somente artigos sobre contabilidade gerencial, que foi o foco do estudo. Ainda, apenas os artigos que eram possíveis de serem baixados. $O$ critério estabelecido para a determinação do artigo como sendo ou não da área da contabilidade gerencial deu-se primeiramente a partir do seu título. Esses artigos foram baixados e se realizou uma leitura preliminar para a constatação de temas relacionados à contabilidade ge- 
rencial, tais como: artefatos da contabilidade, usuários internos, sistema de controle, avaliação de desempenho gerencial, etc.

Na Tabela I apresentam-se a amostra de artigos analisados, segmentado por revista, a indicação do fator de impacto da revista, de acordo com o Journal Citation Reports (JCR), o ano de publicação e a proporção de artigos por revista.

Observa-se que foram identificados 610 artigos relacionados à contabilidade gerencial, sendo que a MAR demonstrou maior quantidade de artigos em todo o período, seguida das revistas AOS e JMAR. Destaca-se que a revista JAL manteve a menor publicação de artigos, devido a indisponibilidade de acesso a esta revista para a observação de seus artigos, sendo que os artigos estavam limitados à consulta local da universidade de origem, de todo o modo, manteve-se esta revista na análise, devido a Hesford et al. (2007) ter a analisado. Além disso, as revistas JMAR e TAR a partir de 2012 possuem seu acesso que era livre, como bloqueado, impossibilitando o download e análise dos artigos.

A amostra de artigos analisados foi segmentada também entre as revistas que possuem editores chefes localizados na Europa e na América do Norte. Os editores chefes constantes na Europa referem-se às revistas AOS e MAR, os quais se encontram na França e Inglaterra, respectivamente e as oito revistas que possuem editores chefes localizados na América do Norte, referem-se à BRIA, JAE, JAL, JAR, JMAR, RAS, TAR (que se encontram nos EUAs) e CAR (a qual possui o editor chefe localizado no Canadá).

TABELA 1 - Amostra de artigos sobre contabilidade gerencial por revistas analisadas e por ano

\begin{tabular}{|c|c|c|c|c|c|c|c|c|c|c|c|}
\hline \multirow[b]{2}{*}{ ANO } & \multicolumn{11}{|c|}{ Revista $\left(\mathrm{JCR}^{*}\right)$} \\
\hline & $\begin{array}{l}\text { AOS } \\
(2.4)\end{array}$ & BRIA & $\begin{array}{l}\text { CAR } \\
(1.7)\end{array}$ & $\begin{array}{l}\text { JAE } \\
(3.5)\end{array}$ & $\begin{array}{l}\text { JAL } \\
(0.8)\end{array}$ & $\begin{array}{l}\text { JAR } \\
(2.2)\end{array}$ & $\begin{array}{c}\text { JMAR } \\
(1.6)\end{array}$ & $\begin{array}{l}\text { MAR } \\
(2.2)\end{array}$ & $\begin{array}{l}\text { RAS } \\
(1.5)\end{array}$ & $\begin{array}{l}\text { TAR } \\
(1.9)\end{array}$ & Total \\
\hline 2001 & 8 & 0 & 2 & 2 & 0 & 2 & 3 & 23 & 1 & 0 & 41 \\
\hline 2002 & 8 & 1 & 2 & 1 & 0 & 1 & 4 & 20 & 0 & 1 & 38 \\
\hline 2003 & 9 & 0 & 0 & 0 & 0 & 0 & 5 & 19 & 0 & 0 & 33 \\
\hline 2004 & 8 & 0 & 7 & 0 & 0 & 0 & 2 & 18 & 0 & 0 & 35 \\
\hline 2005 & 8 & 0 & 3 & 0 & 0 & 0 & 1 & 16 & 0 & 0 & 28 \\
\hline 2006 & 6 & 1 & 2 & 3 & 0 & 0 & 2 & 17 & 0 & 0 & 31 \\
\hline 2007 & 9 & 2 & 1 & 0 & 0 & 1 & 6 & 14 & 1 & 2 & 36 \\
\hline 2008 & 13 & 2 & 3 & 0 & 0 & 2 & 13 & 20 & 1 & 1 & 55 \\
\hline 2009 & 8 & 2 & 0 & 1 & 0 & 0 & 11 & 18 & 0 & 0 & 40 \\
\hline 2010 & 14 & 3 & 1 & 0 & 0 & 0 & 10 & 19 & 1 & 1 & 49 \\
\hline 2011 & 6 & 2 & 4 & 0 & 0 & 4 & 9 & 21 & 0 & 5 & 51 \\
\hline 2012 & 6 & 1 & 1 & 1 & 0 & 3 & 0 & 13 & 0 & 0 & 25 \\
\hline 2013 & 7 & 3 & 1 & 1 & 0 & 4 & 0 & 15 & 0 & 0 & 31 \\
\hline 2014 & 5 & 0 & 3 & 0 & 0 & 0 & 0 & 13 & 1 & 0 & 22 \\
\hline 2015 & 4 & 0 & 2 & 0 & 0 & 1 & 0 & 11 & 0 & 0 & 18 \\
\hline 2016 & 6 & 0 & 3 & 1 & 0 & 1 & 0 & 21 & 0 & 0 & 32 \\
\hline 2017 & 4 & 0 & 4 & 0 & 0 & 0 & 0 & 11 & 2 & 0 & 21 \\
\hline 2018 & 6 & 0 & 3 & 0 & 2 & 2 & 0 & 10 & 1 & 0 & 24 \\
\hline Total & 135 & 17 & 42 & 10 & 2 & 21 & 66 & 299 & 8 & 10 & 610 \\
\hline
\end{tabular}

* Journal Citation Reports (JCR) de 2016.

Fonte: Dados da pesquisa. 
Deste modo, do total de artigos analisados, I 76 eram da Europa e 434 da América do Norte. Como o intuito do estudo é observar evidências atualizadas em relação à Hesford et al. (2007), realizou-se esta segmentação de análise de artigos publicados em revistas na Europa e na América do Norte para observar se nos últimos anos a diferenciação de estudos entre os continentes se mantiveram ou não.

Optou-se por analisar artigos do período de 2001 a 20I8, aqui nominada de Período 2, período após a publicação de Hesford et al. (2007) - nominada como Período I. Espera-se que a análise comparativa entre os achados aqui descritos com os do estudo base forneçam uma visão longitudinal da evolução das pesquisas durante décadas.

Tem-se como limitações a não disponibilidade de download de alguns artigos de contabilidade gerencial publicados nas revistas, o que comprometeu a quantidade de artigos analisados. Também, analisou-se elementos dos artigos que Hesford et al. (2007) já analisada, entretanto realizou-se a operacionalização dos artigos em período posterior ao autor.

A coleta dos artigos foi realizada a partir do acesso à página das dez revistas analisadas. Inicialmente procedeu-se uma busca por ano e edição dos artigos sobre contabilidade gerencial. Nessa fase, a análise preliminar foi pelo título e resumo do artigo. Por sua vez, para a análise dos dados, procedeu-se a compilação de informações em quadros, tabelas ou figuras, as quais tiverem por intuito classificar os artigos por tema, métodos de investigação, teorias utilizadas e demais perspectivas teóricas agrupadas de acordo com:i) o período analisado; ii) revistas; iii) temática na contabilidade gerencial. Procedeu-se também a análise das carac- terísticas de autoria, como a quantidade de artigos por autor e a quantidade de autor por artigo. Por fim, analisou-se a rede social de autores que apresentaram três ou mais artigos publicados nas revistas e no período analisado. Os dados foram tabulados e organizados por meio de planilha eletrônica e para os cálculos utilizou-se da análise de frequência. Para a realização das redes sociais utilizou-se o software UNICET 6.

\section{DESCRIÇÃO E ANÁLISE DOS DADOS}

\section{Classificação dos Artigos por Temas, Métodos de Investigação e Teorias em Relação ao Período de Investigação}

Demonstra-se na Tabela 2 a classificação dos artigos por tema de investigação observados nos artigos sobre contabilidade gerencial no período analisado, bem como a comparação com os dados observados no estudo base.

Para análise dos dados o Período I diz respeito aos dados oriundos do estudo de Hesford et al. (2007) e o Período 2 coletados na presente pesquisa. Observa-se que o tema mais investigado no atual estudo foi o controle, seguido por outros temas e após custos, respectivamente, sendo que no estudo base de Hesford et al. (2007) as publicações se concentraram inicialmente também em temas sobre controle, após sobre custos e por fim outros temas. Deste modo, percebe-se que na década mais atual, o tema controle continuou sendo investigado, porém o tema custos teve redução no número de publicações que foi compensado pelo aumento de artigos realizadas sobre outros temas de contabilidade gerencial. No conjunto (três décadas), a essência de análise foi sobre o tema de controle, seguida de outros temas de 
TABELA 2 - Classificação dos artigos por tema de investigação e período

\begin{tabular}{|c|c|c|c|c|c|c|}
\hline \multirow[t]{2}{*}{ TEMAS DE PESQUISA } & \multicolumn{2}{|c|}{ Período 1(1981 - 2000) } & \multicolumn{2}{|c|}{ Período 2(2001-2018) } & \multicolumn{2}{|c|}{ Ambos (1981-2018) } \\
\hline & Qt. & $\%$ & Qt. & $\%$ & Qt. & $\%$ \\
\hline \multicolumn{7}{|l|}{ Custos } \\
\hline Alocação de custos & 140 & 15 & 39 & 6,40 & 179 & 11,80 \\
\hline Outros tópicos de contab. de custos & 21 & 2 & 14 & 2,30 & 35 & 2,30 \\
\hline Práticas de custos & 15 & 3 & 19 & 3,12 & 34 & 2,24 \\
\hline Assimetria de custos & 0 & 0,00 & 5 & 0,81 & 5 & 0,32 \\
\hline Total de custos & 176 & 20 & 77 & 12,63 & 253 & 16,67 \\
\hline \multicolumn{7}{|l|}{ Controle } \\
\hline Orçamento & 134 & 15 & 68 & 11,14 & 202 & 13,31 \\
\hline Orçamento de capital & 47 & 5 & 9 & 1,48 & 56 & 3,69 \\
\hline Mensuração e avaliação de desempenho & 148 & 16 & 122 & 20 & 270 & 17,79 \\
\hline Controle organizacional & 296 & 32 & 240 & 39,34 & 536 & 35,31 \\
\hline Controle internacional & 16 & 2 & 0 & 0 & 16 & 1,04 \\
\hline Total de controle & 641 & 70 & 439 & 71,96 & 1080 & 71,14 \\
\hline \multicolumn{7}{|l|}{ Outros } \\
\hline AIS (sistema de controle) & 7 & 0,75 & 12 & 1,97 & 19 & 1,24 \\
\hline Benchmarking & 2 & 0,25 & 0 & 0 & 2 & 0,13 \\
\hline Qualidade total (TQM) & 9 & 1 & 1 & 0,17 & 10 & 0,64 \\
\hline Just-in-time (JIT) & 7 & 1 & 4 & 0,66 & 11 & 0,72 \\
\hline Métodos de pesquisa & 20 & 2 & 24 & 3,93 & 44 & 2,90 \\
\hline Gerenciamento estratégico & 15 & 2 & 23 & 3,78 & 39 & 2,55 \\
\hline Preços de transferência & 31 & 3 & 15 & 2,45 & 46 & 3,03 \\
\hline Mudanças na contab. gerencial & 0 & 0,00 & 15 & 2,45 & 15 & 0,98 \\
\hline Total de outros & 91 & 10 & 94 & 15,41 & 185 & 12,19 \\
\hline Total & 908 & 100 & 610 & 100 & 1518 & 100 \\
\hline
\end{tabular}

Legenda: * dados do estudo de Hesford et al. (2007).

Fonte: Dados da pesquisa.

contabilidade gerencial e por fim o tema de custos.

Em relação ao tema mais investido sobre controle no período analisado, destaca-se pesquisas sobre mensuração e avaliação de desempenho, enquanto que no estudo de Hesford et al. (2007), a concentração maior de estudos era sobre controle organizacional. $O$ tema mais investigado tanto no atual estudo, quanto no estudo base foi à alocação de custos, no entanto, constata-se o início de publicações sobre assimetria de custos a partir de 2001. A partir de 2010 houve alteração de temas de investigação, com maior atenção para o tema de mensuração e avaliação de desempenho, ao contrário de controle organizacional. Ainda, observou-se que a partir de 200 I surgiram novas temáticas de investigação, tais como: assimetria de custos (temática custos) e mudanças na contabilidade gerencial (outros temas). Apresenta-se na Tabela 3 a classificação dos artigos por método de investigação e período analisado.

Percebe-se que na década mais atual o método mais utilizado em estudos de contabilidade gerencial foi o de levantamento de dados, seguido de estudo de caso e experimento, em que no estudo base os métodos mais utilizados foram quadro conceitual, analítico e levantamento de dados. Percebe-se uma mudança nas preferências 
TABELA 3 - Classificação dos artigos por método de investigação e período

\begin{tabular}{|c|c|c|c|c|c|c|}
\hline Método de Pesquisa & $\begin{array}{c}\text { Período } 1 \\
1981-2000^{*}\end{array}$ & $\% *$ & $\begin{array}{l}\text { Período } 2 \\
2001-2018\end{array}$ & $\%$ & $\begin{array}{c}\text { Ambos } \\
1981-2018\end{array}$ & $\%$ \\
\hline Analítico & 169 & 19 & 86 & 14,10 & 255 & 16,71 \\
\hline Arquivo & 78 & 9 & 45 & 7,37 & 123 & 8,06 \\
\hline Campo & 91 & 10 & 62 & 10,17 & 153 & 10,02 \\
\hline Caso & 78 & 9 & 72 & 11,80 & 150 & 9,82 \\
\hline Experimento & 116 & 12 & 84 & 13,78 & 200 & 13,10 \\
\hline Quadro Conceitual & 179 & 19 & 27 & 4,42 & 206 & 13,50 \\
\hline Levantamento de dados & 149 & 16 & 165 & 27,04 & 314 & 20,58 \\
\hline Múltiplos & 7 & 1 & 3 & 0,50 & 10 & 0,65 \\
\hline Revisão de literatura & 49 & 5 & 48 & 7,87 & 97 & 6,37 \\
\hline Outros (Ensaio teórico e bibliométrico) & 0 & 0 & 18 & 2,95 & 18 & 1,19 \\
\hline Total & 916 & 100 & 610 & 100 & 1526 & 100 \\
\hline
\end{tabular}

Legenda: * dados do estudo de Hesford et al. (2007).

Fonte: Dados da pesquisa

de métodos utilizados nas pesquisas de contabilidade gerencial, sendo que o levantamento de dados continuou sendo priorizado, além de estudo de caso, porém, observa-se a utilização de experimentos nos anos mais atuais, sendo que nas primeiras duas décadas era menos utilizado este tipo de método, que possui pressupostos vindos principalmente da psicologia.

Constata-se de acordo com a Tabela 2 e 3 , que os temas não foram bruscamente alterados de um período para outro, porém os métodos utilizados sim. Infere-se, deste modo, que as revistas em análise deram ênfase a artigos que buscaram analisar questões fundamentais da contabilidade gerencial, porém com a utilização de métodos diferenciados. Na sequência, a Tabela 4 indica a classificação dos artigos por teoria utilizada e por período.

Com base na Tabela 4, percebe-se que as teorias mais utilizadas nos estudos atuais de contabilidade gerencial são oriundas da economia, assim como também foi observado pelo estudo de Hesford et al. (2007). Entretanto, observou-se que no atual período, após as teorias de economia, teve-se maior utiliza- ção de teorias advindas da psicologia, comparativamente aquelas originadas da sociologia, o que foi observado ao contrário pelo estudo base. $O$ crescimento de publicações amparadas na psicologia pode ser explicado pelo crescente interesse no uso do método de experimento no Período dois.

Ainda, constatou-se de acordo com a tabela, de que teorias vindas de outras áreas (além de economia, psicologia e sociologia) estão sendo utilizadas em maior quantidade, do que no estudo base. Este achado possibilita a inferência de que as revistas em análise, a fim de desenvolver a contabilidade gerencial e obter outras explicações sobre os fatos contábeis, estão buscando explicações e previsões de outras teorias, tais como filosofia e física, o que contribui para o desenvolvimento da contabilidade gerencial.

\section{Classificação dos Artigos por Temas, Métodos de Investigação e Teorias Organizacionais em Relação às Revistas Analisadas}

Apresentam-se na Tabela 5 as características das revistas por temas investigados tanto do período atual analisado, quanto do 
TABELA 4 - Classificação dos artigos por teoria utilizada e período

\begin{tabular}{|c|c|c|c|c|c|c|}
\hline Área de conhecimento & $\begin{array}{c}\text { Período } 1 \\
1981-2000^{*}\end{array}$ & $\%^{*}$ & $\begin{array}{l}\text { Período } 2 \\
2001-2018\end{array}$ & $\%$ & $\begin{array}{c}\text { Ambos } \\
1981-2018\end{array}$ & $\%$ \\
\hline \multicolumn{7}{|l|}{ Economia } \\
\hline Economia & 360 & 39 & 327 & 53,60 & 687 & 45,02 \\
\hline Economia/Psicologia & 13 & 2 & 28 & 4,60 & 41 & 2,69 \\
\hline Economia/Sociologia & 20 & 2 & 13 & 2,13 & 33 & 2,17 \\
\hline Economia/Várias Teorias & 3 & 1 & 2 & 0,32 & 5 & 0,32 \\
\hline Total de Economia & 396 & 44 & 370 & 60,65 & 766 & 50,20 \\
\hline \multicolumn{7}{|l|}{ Psicologia } \\
\hline Psicologia & 121 & 12 & 88 & 14,42 & 209 & 13,69 \\
\hline Psicologia/Economia & 4 & 1 & 4 & 0,65 & 8 & 0,52 \\
\hline Psicologia/Sociologia & 15 & 2 & 3 & 0,50 & 18 & 1,18 \\
\hline Total de Psicologia & 140 & 15 & 95 & 15,57 & 235 & 15,39 \\
\hline \multicolumn{7}{|l|}{ Sociologia } \\
\hline Sociologia & 320 & 34 & 106 & 17,37 & 426 & 27,92 \\
\hline Sociologia/Economia & 19 & 2 & 2 & 0,33 & 21 & 1,37 \\
\hline Sociologia/Psicologia & 23 & 3 & 2 & 0,33 & 25 & 1,64 \\
\hline Total de Sociologia & 362 & 39 & 110 & 18,03 & 472 & 30,93 \\
\hline \multicolumn{7}{|l|}{ Outros } \\
\hline História & 4 & 0,44 & 0 & 0,00 & 4 & 0,26 \\
\hline $\begin{array}{l}\text { Teorias de mais de uma área de } \\
\text { conhecimento }\end{array}$ & 12 & 1,31 & 28 & 4,60 & 40 & 2,63 \\
\hline Varias teorias/Economia & 2 & 0,22 & 6 & 0,99 & 8 & 0,53 \\
\hline Física & 0 & 0 & 0 & 0,00 & 0 & 0,00 \\
\hline Filosófico & 0 & 0 & 1 & 0,16 & 1 & 0,06 \\
\hline Total de Outras & 18 & 2 & 35 & 5,75 & 53 & 3,48 \\
\hline Total & 916 & 100 & 610 & 100 & 1526 & 100 \\
\hline
\end{tabular}

Legenda: * dados do estudo de Hesford et al. (2007).

Fonte: Dados da pesquisa

período de I98I a 2000, do estudo de Hesford et al. (2007). Além disso, comparam-se as publicações das duas revistas europeias - AOS e MAR, em relação às demais.

No que se refere aos temas investigados, em comparação com os achados de Hesford et al. (2007), observa-se que as revistas AOS, BRIA, JAR, JMAR, MAR, RAS e TAR continuaram em maior medida a publicar artigos sobre controle gerencial. Já as revistas CAR e JAE passaram a publicar em maior concentração artigos sobre outros temas de contabilidade gerencial, que não se relacionam com controle e custos. Observou-se, no Período 2, uma redução no número de publicações relacionadas com a temática de custos e sua evolução.

No Período 2, as revistas da Europa e da América apresentaram mesmas proporções de artigos publicados sobre custos, já no estudo de Hesford et al. (2007), teve-se maior concentração de estudos publicados sobre custos nas revistas americanas. Em relação aos estudos sobre outros temas de contabilidade gerencial, a maior proporção na última década foi nas revistas europeias, entretanto no estudo base a maior concentração foi nas outras oito revistas que são americanas. Apresenta-se na Tabela 6 a frequência de publicação de artigos sobre 
TABELA 5 - Características das revistas por temas investigados

\begin{tabular}{|c|c|c|c|c|c|c|}
\hline \multirow[t]{2}{*}{ REVISTAS } & \multicolumn{3}{|c|}{ Período $1(1981-2000)^{*}$} & \multicolumn{3}{|c|}{ Período 2 (2001-2018) } \\
\hline & Custos* & Controle* & Outros* & Custos & Controle & Outros \\
\hline & $\%$ & $\%$ & $\%$ & $\%$ & $\%$ & $\%$ \\
\hline AOS & 5 & 85 & 9 & 10 & 49 & 41 \\
\hline BRIA & 0 & 77 & 22 & 8 & 69 & 23 \\
\hline CAR & 24 & 66 & 8 & 28 & 24 & 48 \\
\hline JAE & 13 & 78 & 7 & 15 & 43 & 42 \\
\hline JAL & 21 & 64 & 14 & 0 & 0 & 0 \\
\hline JAR & 24 & 68 & 7 & 14 & 53 & 33 \\
\hline JMAR & 22 & 52 & 17 & 13 & 71 & 16 \\
\hline MAR & 24 & 65 & 9 & 9 & 66 & 25 \\
\hline RAS & 23 & 52 & 23 & 12 & 76 & 12 \\
\hline TAR & 31 & 64 & 3 & 0 & 100 & 0 \\
\hline AOS e MAR & 13 & 76 & 9 & 9 & 61 & 30 \\
\hline Outras Oito Revistas & 24 & 63 & 11 & 15 & 69 & 16 \\
\hline Total & 20 & 70 & 10 & 14 & 52 & 34 \\
\hline
\end{tabular}

Legenda: * dados do estudo de Hesford et al. (2007).

Fonte: Dados da pesquisa.

contabilidade gerencial de acordo com os métodos e por revistas.

Ao se comparar as revistas da Europa com as da América, observa-se que nas primeiras duas décadas as revistas europeias preferiram o método quadro conceitual, já na última década deram preferência ao método de levantamento de dados. Por outro lado, as revistas americanas, nas primeiras décadas, preferiram o método analítico e na última década os métodos experimento e levantamento de dados. Deste modo, pode-se inferir que a retomada do método experimento em artigos de contabilidade gerencial, se deve principalmente às publicações de artigos em revistas americanas. Apresenta-se a Tabela 7 as características das revistas por teorias utilizadas.

De acordo com a Tabela 7, nas primeiras duas décadas observadas por Hesford et al. (2007) as revistas AOS e a MAR publicaram mais artigos com cunho teórico vindo da sociologia e a revista BRIA da psicologia, entretanto na última década, observado pelo atual estudo, a tendência foi a pu- blicação de artigos por estas revistas com cunho teórico econômico. As demais revistas, nos trinta anos analisados, demonstraram a tendência de publicação de artigos com cunho teórico econômico, devido aos resultados constantes na Tabela 7 e à aproximação com a área da contabilidade gerencial.Ao se analisar as revistas da Europa e da América observam-se que nas primeiras duas décadas as revistas europeias preferiram artigos com cunho sociológico, já nas últimas décadas a preferência foi por cunho econômico. Já as revistas americanas ao longo dos 30 anos publicaram mais artigos com cunho econômico.

\section{Relação entre Métodos, Temas e Teorias}

Em se tratando da relação entre os métodos de pesquisa com as teorias utilizadas nas pesquisas em contabilidade gerencial, dentre as pesquisas que utilizaram como base teorias advindas da psicologia, na última década, utilizaram com maior frequência o método experimento e também levantamento de dados, já nas primeiras duas 
TABELA 6 - Características das revistas por métodos em percentagem

\begin{tabular}{|c|c|c|c|c|c|c|c|c|c|c|c|c|c|}
\hline MÉTODOS & $\begin{array}{l}0 \\
\text { OO }\end{array}$ & $\begin{array}{l}\frac{\Delta}{\alpha} \\
\frac{\alpha}{\infty}\end{array}$ & $\frac{\alpha}{\delta}$ & 岩 & $\frac{1}{S}$ & $\underset{S}{\frac{\alpha}{S}}$ & 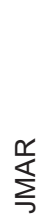 & $\stackrel{\frac{\alpha}{\alpha}}{\Sigma}$ & 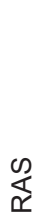 & $\underset{\frac{\alpha}{r}}{\underline{r}}$ & 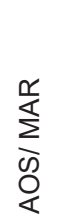 & 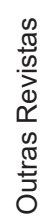 & $\begin{array}{l}\bar{\pi} \\
\overline{0}\end{array}$ \\
\hline Analítico* & 0 & 0 & 64 & 39 & 0 & 54 & 12 & 8 & 90 & 33 & 4 & 33 & 18 \\
\hline Analítico & 12 & 3 & 5 & 2 & 0 & 10 & 0 & 65 & 0 & 3 & 78 & 22 & 14 \\
\hline Arquivo* & 2 & 0 & 7 & 50 & 0 & 11 & 13 & 4 & 10 & 16 & 3 & 14 & 8,5 \\
\hline Arquivo & 9 & 0 & 4 & 2 & 0 & 20 & 26 & 31 & 8 & 0 & 40 & 60 & 7 \\
\hline Caso* & 7 & 3 & 0 & 3 & 0 & 0 & 3,5 & 27 & 0 & 2 & 15 & 2 & 8,5 \\
\hline Caso & 26 & 0 & 3 & 1 & 0 & 0 & 5 & 64 & 1 & 0 & 86 & 14 & 11 \\
\hline Experimento* & 10 & 37 & 15 & 2 & 0 & 23 & 16 & 3 & 0 & 24 & 7 & 17 & 12 \\
\hline Experimento & 30 & 10 & 16 & 0 & 0 & 7 & 20 & 15 & 1 & 1 & 45 & 55 & 13 \\
\hline Campo* & 18 & 0 & 2 & 0 & 0 & 1,5 & 9 & 16 & 0 & 1 & 17 & 3 & 10 \\
\hline Campo & 35 & 0 & 8 & 0 & 0 & 0 & 6 & 49 & 0 & 2 & 85 & 15 & 10 \\
\hline Quadro Conceitual* $^{*}$ & 32 & 28 & 0 & 0 & 0 & 1,5 & 24 & 25 & 0 & 8 & 29 & 10 & 20 \\
\hline Quadro Conceitual & 33 & 4 & 0 & 4 & 0 & 0 & 0 & 63 & 0 & 0 & 96 & 4 & 5 \\
\hline Revisão da Literatura* & 3 & 14 & 2 & 3 & 96 & 2 & 3 & 2 & 0 & 0 & 2,5 & 8 & 5 \\
\hline Revisão da Literatura & 39 & 0 & 2 & 2 & 0 & 0 & 14 & 43 & 0 & 0 & 83 & 17 & 8 \\
\hline Levantamento Dados* & 26 & 7 & 9 & 3 & 0 & 7 & 9 & 15 & 0 & 13 & 21 & 11 & 16 \\
\hline Levantamento Dados & 19 & 3 & 8 & 3 & 1 & 2 & 8 & 50 & 1 & 3 & 70 & 30 & 28 \\
\hline Múltiplos* & 0 & 0 & 0 & 0 & 0 & 0 & 0 & 0 & 0 & 0 & 0 & 0 & 0 \\
\hline Múltiplos & 0 & 0 & 0 & 0 & 0 & 33 & 0 & 67 & 0 & 0 & 67 & 33 & 1 \\
\hline Outros* & 1 & 0 & 0 & 0 & 4 & 0 & 1 & 1 & 0 & 3 & 1,5 & 2 & 2 \\
\hline Outros & 17 & 0 & 0 & 0 & 0 & 0 & 5 & 78 & 0 & 0 & 94 & 6 & 3 \\
\hline
\end{tabular}

Legenda: * Dados do estudo de Hesford et al. (2007).

Fonte: Dados da pesquisa.

TABELA 7 - Características das revistas por teorias utilizadas em percentagem

\begin{tabular}{|c|c|c|c|c|c|c|c|c|c|c|c|c|c|}
\hline Teorias & On & $\frac{\overleftarrow{r}}{\underline{\underline{r}}}$ & $\frac{\alpha}{\delta}$ & 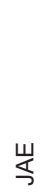 & $\frac{1}{s}$ & $\frac{\alpha}{\frac{\alpha}{S}}$ & $\sum_{j}^{\frac{\alpha}{\alpha}}$ & $\sum_{\Sigma}^{\frac{\alpha}{\Sigma}}$ & $\underset{\Phi}{\Phi}$ & $\underset{\leftarrow}{\frac{\alpha}{L}}$ & $\begin{array}{l}\frac{\alpha}{\alpha} \\
\sum_{0} \\
0 \\
0 \\
0\end{array}$ & 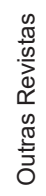 & 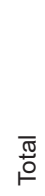 \\
\hline Econômica* & 12 & 8 & 76 & 94 & 53 & 71 & 37 & 30 & 100 & 60 & 20 & 58 & 39 \\
\hline Econômica & 19 & 2 & 8 & 2 & 0 & 3 & 14 & 49 & 1 & 2 & 66 & 34 & 61 \\
\hline Psicologia* & 15 & 34 & 13 & 0 & 0 & 21 & 16 & 5 & 0 & 19 & 10 & 16 & 13 \\
\hline Psicologia & 27 & 10 & 10 & 1 & 1 & 6 & 4 & 38 & 1 & 2 & 66 & 34 & 15 \\
\hline Sociologia* & 60 & 28 & 5 & 0 & 18 & 3 & 23 & 56 & 0 & 11 & 58 & 12 & 35 \\
\hline Sociologia & 37 & 1 & 0 & 1 & 0 & 3 & 4 & 52 & 1 & 1 & 89 & 11 & 18 \\
\hline Outras* & 0 & 0 & 2 & 0 & 0 & 2 & 9 & 2 & 0 & 1 & 1 & 3 & 2 \\
\hline Outras & 16 & 0 & 16 & 16 & 16 & 0 & 16 & 20 & 0 & 0 & 50 & 50 & 1 \\
\hline Múltiplas* & 13 & 28 & 4 & 5 & 28 & 3 & 15 & 6 & 0 & 9 & 10 & 11 & 11 \\
\hline Múltiplas & 0 & 0 & 0 & 0 & 0 & 3 & 10 & 87 & 0 & 0 & 86 & 14 & 5 \\
\hline
\end{tabular}

Legenda: * Dados do estudo de Hesford et al. (2007).

Fonte: Dados da pesquisa 
décadas, a predominância foi a utilização do método experimento. Deste modo, inferese que na última década, a fim de explicar o comportamento dos indivíduos relacionado com informações gerenciais, além de as pesquisas utilizarem o método experimento, utilizaram também levantamento de dados, como questionário e/ou entrevista.

Dentre os estudos que utilizaram como base teorias da sociologia, o método predominante de 200 I a 20 II foi o estudo de caso, já de 199I a 2000 o método predominante foi o quadro conceitual. As pesquisas que utilizaram outras teorias, além das econômicas, psicológicas e sociológicas, utilizaram como base na última década o método experimento e outros métodos (como ensaio teórico ou bibliométrico), já nas primeiras décadas destacou-se o método quadro conceitual. Os estudos que utilizaram múltiplas teorias (econômica, psicológica e sociológica, ao mesmo tempo) utilizaram mais na última década o método revisão de literatura e nas primeiras duas décadas o método de levantamento de dados.

Os métodos, tais como analítico, arquivo, revisão de literatura e outros nos 30 anos foram mais utilizados em pesquisa com cunho teórico advindo da economia. No primeiro período de análise os artigos que utilizaram teorias originadas da sociologia demonstraram mais a utilização dos métodos estudo de caso, campo, quadro conceitual e levantamento de dados, já no segundo período os artigos que utilizaram teorias vindas da economia é que se pautaram mais nestes métodos. $O$ método experimento também foi mais observado nos últimos anos em pesquisas com teorias da economia, enquanto que nos primeiros em pesquisas com teorias psicológicas. Por fim, as pesquisas que utilizaram mais de um método de pesquisa também se basearam em teorias da economia, essencialmente na última década.

Quanto a relação das teorias com os temas de pesquisa, dentre as pesquisas com o tema custos, nos 30 anos, foram utilizadas mais teorias da economia, bem como os temas controle e outros temas de contabilidade gerencial, em que também se tem predominância de teorias advindas da economia nos últimos anos. Por outro lado, de acordo com o estudo de Hesford et al. (2007) as pesquisas que possuem o tema controle e outros temas de contabilidade gerencial se pautaram mais em teorias sociológicas. Quanto ao painel B da tabela, observa-se que o tema mais investigado nos últimos 30 anos, utilizando teorias econômicas, psicológicas e sociológicas foi o controle, sendo que nos últimos II anos, as pesquisas que analisaram outros temas de contabilidade gerencial utilizaram também múltiplas teorias ou outras teorias além das econômicas, psicológicas e sociológicas.

\section{Características de Autoria e Redes Sociais}

Apresenta-se nesta seção características de autoria evidenciadas na Tabela 8, a qual apresenta a quantidade de artigos por autores e o número de autores por artigo.

$\mathrm{Em}$ relação ao número de artigos por autor, observa-se que mais da metade dos autores $(76,45 \%)$ publicaram somente um artigo de contabilidade gerencial no período e nas revistas analisadas, sendo que $7,86 \%$ de autores possuem três ou mais artigos publicados. Este resultado está de acordo com o observado por Hesford et al. (2007), o qual também demonstrou que, no período entre 1991 e 2000 a maioria dos autores publicaram apenas um artigo. Observou-se que são poucos os autores que 
TABELA 8 - Quantidade de artigos por autores e número de autores por artigo, período 2001 a 2011

\begin{tabular}{c|c|c|c|c|c}
\hline Número de Artigos & Autores & $\%$ & $\begin{array}{c}\text { Número de } \\
\text { Autores }\end{array}$ & Artigos & \% \\
\hline 1 & 341 & 76,45 & 1 & 157 & 24,74 \\
\hline 2 & 70 & 15,69 & 2 & 177 & 39,83 \\
\hline 3 & 21 & 4,71 & 3 & 29 & 4,76 \\
\hline 4 & 8 & 1,79 & 4 & 4 & 0,65 \\
\hline 5 & 3 & 0,68 & 5 & - & - \\
\hline 7 & 2 & 0,45 & - & & \\
\hline Total & 1 & 0,23 & - & & \\
\hline
\end{tabular}

Fonte: Dados da pesquisa

estão de fato publicando assuntos de contabilidade gerencial em uma linha evolutiva do conhecimento, que poderia contribuir com o desenvolvimento e amadurecimento da contabilidade gerencial. Entretanto, deve-se ressaltar que as revistas analisadas possuem alto impacto acadêmico, deste modo, deve-se ponderar que é complexo publicar em tais revistas.

No que se refere ao número de autores por artigo, $65,57 \%$ são de no máximo dois autores. Talvez uma maneira de auxiliar o desenvolvimento das pesquisas em contabilidade gerencial, seja trabalhar a pesquisa colaborativa, em oposição ao individual. Desse modo, embora a pesquisa colaborativa possa ser complexa, para o desenvolvimento da contabilidade gerencial é salutar, haja vista que contribui para a interdisciplinaridade e multidisciplinaridade dos fenômenos contábeis gerenciais estudados. Comparativamente ao estudo de Hesford et al. (2007), percebe-se uma evolução, já que nele a maioria dos artigos apresentavam um autor.

Apresenta-se de acordo com a Figura I a rede social de pesquisa de autores com mais de três artigos publicados (de acordo com a Tabela 8), sendo que para a construção desta rede a única delimitação foi o número de artigos publicados por autor.

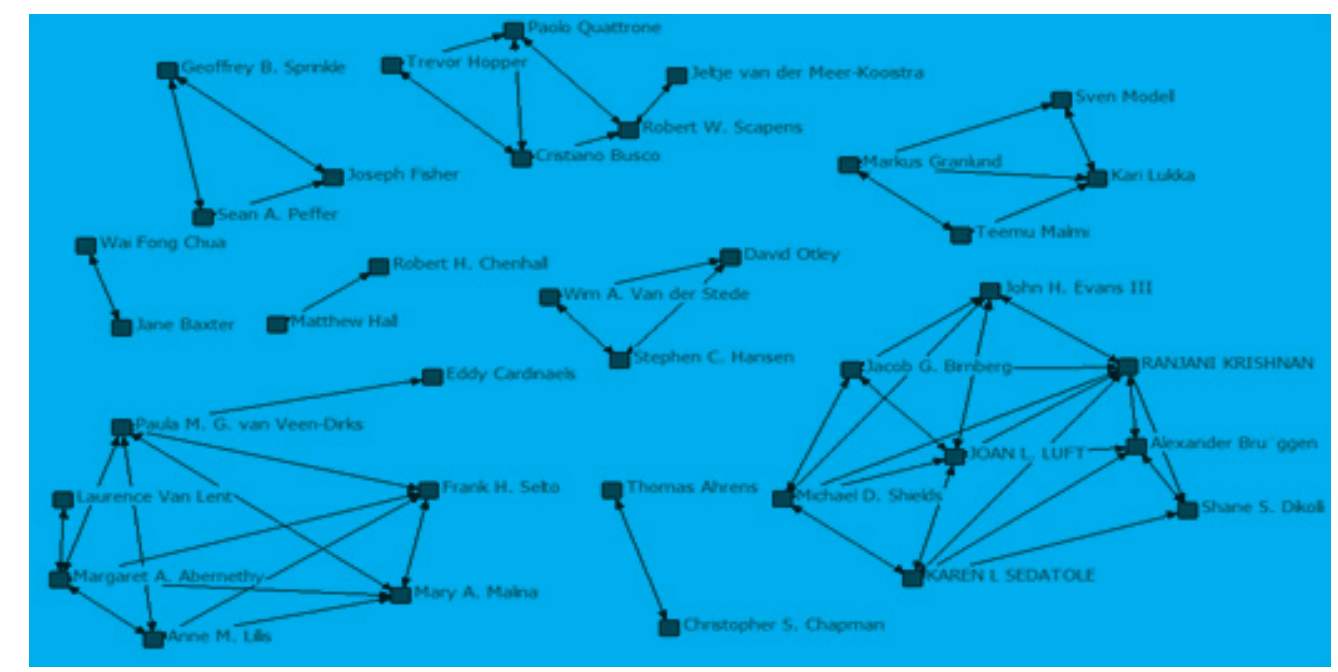

FIGURA 1 - Rede social de autores com três ou mais artigos publicados nas revistas e no período analisado

Fonte: Dados da pesquisa. 
Observa-se que no período e nas revistas analisadas, há duas principais redes de autores, em que uma apresenta menção a autores tais como: Frank H. Selto, Mary A. Malina, Paula M. G. Van Veen-Dirks, Anne M. Lilis e demais autores. Já a outra principal rede apresenta menção a autores tais como: Ranjani Krishman, Alexander Brüggen, Karen Sedatole, Joan L. Luft e outros. Percebem-se outras pequenas redes, como a formada por Wim A.Van der Stede e David Otley. Estas redes demonstram a interatividade dos autores em trabalhar em conjunto devido à proximidade de temas, métodos, teorias ou experiências.

De acordo com Neiva e Corradi (2010), as redes sociais de autores permitem a troca de informações e conhecimento entre os pesquisadores de uma ou mais instituições, com exposição, compartilhamento, discussão e análise de ideias, permitindo a liberdade, criatividade e novas abordagens para a resolução de problemas. Deste modo, infere-se que quando determinada área de conhecimento possui poucas redes de autores, esta pode estar perdendo oportunidades de evolução. Assim, observa-se na área de contabilidade gerencial a formação de redes de autores de diferentes instituições, entretanto, ainda há poucos autores se envolvendo neste processo.

\section{Discussão dos Resultados e Perspectivas Futuras de Pesquisa em Contabilidade Gerencial}

Os resultados evidenciados no estudo demonstram que as pesquisas sobre custos têm perdido espaço para outros temas de contabilidade gerencial, principalmente para o sistema de controle gerencial. Observa-se duas novas temáticas de estudo, tais como assimetria de custos (tema cus- tos) e mudanças na contabilidade gerencial (outros temas), o que demonstra a evolução da pesquisa em relação a temáticas diferenciadas que possam contribuir para o desenvolvimento da área.

A contabilidade gerencial deve se atualizar a fim de prescrever práticas capazes de suprir informações adequadas às novas exigências decisórias (SOUZA; LISBOA; ROCHA, 2003), para ajudar as empresas a enfrentar os desafios globais nos mercados competitivos (BROMWICH, 1990). Deste modo, indica-se com base nos resultados do atual estudo sobre os temas investigados, que devido às incertezas econômicas que se encontram presentes em todo o mundo desde 2007, as pesquisas em contabilidade gerencial estão, de certa forma, podendo contribuir com as decisões das empresas. Isto em decorrência da investigação de sistemas de controle gerencial e custos, que possam auxiliar na avaliação do desempenho das empresas, uma vez, que estas necessitam encontrar maneiras de se estabilizar em um mercado competitivo e instável. As pesquisas em contabilidade gerencial se aproximando da realidade da empresa poderiam auxiliar na adaptação dos sistemas para a continuidade no mercado.

Em relação aos métodos mais empregados nas pesquisas em contabilidade gerencial observou-se o levantamento de dados, seguido de estudo de caso e experimento, já no estudo de Hesford et. al (2007) os métodos mais utilizados foram quadro conceitual, analítico e levantamento de dados. Deste modo, percebeu-se uma alteração dos métodos mais empregados, sendo que se diminuíram as pesquisas teóricas e preocupou-se mais em pesquisas com dados empíricos, fato ocorrido devido a linha positiva da contabilidade. 
Além disso, observou-se que o método experimento, voltou a ser utilizado nas pesquisas em contabilidade gerencial na última década, o que pode contribuir com as pesquisas em contabilidade gerencial, por demonstrar em cenários fechados (moldados) as práticas gerencias das empresas e o comportamento dos indivíduos em relação as mesmas. De certa forma, observou-se a tendência dos pesquisadores gerenciais em buscar métodos que trouxessem informações das empresas o mais real possível, pela utilização em maior grau de levantamento de dados, como questionário e entrevista, estudo de caso e experimento. Inferese desta forma que, para contribuir com o avanço da pesquisa gerencial, de acordo com os estudos observados, o ideal seria utilizar informações internas, e quando não possível, se utilizar de experimentos, para criar um cenário semelhante ao vivido pelas organizações. Somado a isto, de acordo com Van der Stede, Young e Chen (2007) os pesquisadores devem dar maior atenção aos métodos que são utilizados, para que forneçam maior credibilidade científica à pesquisa.

Quanto às teorias, observou-se que as mais utilizadas foram às advindas da economia, seguido da psicologia e após da sociologia. Este resultado se alterou em relação ao estudo de Hesford et al. (2007), pois de 1981 a 2000 , se tinha mais pesquisas com base na sociologia do que na psicologia. Este resultado pode estar atrelado também à retomada de utilização do método experimento, uma vez que ele é originado da psicologia. Estes resultados revelam que os pesquisadores em contabilidade gerencial devem analisar os fatos gerenciais não somente pelo viés econômico, mas também realizar investigações de como os ar- tefatos gerenciais impactam ou são impactados pelo comportamento dos indivíduos (psicologia) e como possuem relação com a sociedade como um todo (sociologia). Além disso, observa-se a preocupação, nas pesquisas analisadas, em buscar explicações de fatos gerenciais em outras áreas também, além dos já mencionados, como da filosofia e da física.

Esta inferência já fora mencionada por Covaleski, Dirsmith e Samuel (1996) de que as pesquisas em contabilidade gerencial de maneira geral estão conseguindo se utilizar de outras teorias para examinar o desenvolvimento, manutenção e mudança nas práticas de contabilidade gerencial, para contribuir para a reformulação e avanço da área. Porém, estes autores observaram a utilização de teorias organizacionais e sociológicas, sendo que as evidências do atual estudo podem inferir que as pesquisas em contabilidade gerencial a fim de desenvolver a área, estão se utilizando também de teorias advindas da psicologia, filosofia e física.

Ao se analisar as tendências de pesquisas por revistas constatou-se que, de maneira geral, as revistas americanas publicaram mais artigos sobre o tema controle, já as revistas europeias publicaram um pouco menos sobre o tema controle e mais sobre outros temas de contabilidade gerencial. Quanto aos métodos, as revistas europeias têm preferido o método de levantamento de dados e as americanas além do levantamento de dados, o experimento.

Quanto às características dos autores e rede social, observou-se que a maioria dos autores publicaram somente um artigo em contabilidade gerencial, sendo poucos os que veem contribuindo para a área com cinco ou mais artigos. Constatou-se que os autores têm priorizado a publicação indi- 
vidual ou no máximo com uma parceria, como consequência, as redes sociais foram fracas, com ocorrência de duas redes principais, porém pequenas. $O$ baixo índice de parceria nas pesquisas e a fragilidade das redes sociais são prejudiciais para o desenvolvimento da contabilidade, visto que inibe a troca de informações, conhecimentos, compartilhamento de novas abordagens de pesquisa, interatividade entre pesquisadores de diferentes instituições. Deste modo, é necessário que os pesquisadores de contabilidade gerencial promovam parcerias para o desenvolvimento das pesquisas, procedimento que pode auxiliar na evolução do conhecimento da área gerencial.

\section{CONSIDERAÇÕES FINAIS}

A pesquisa teve a finalidade de realizar um estudo bibliométrico da contabilidade gerencial. $O$ estudo buscou analisar quais foram os temas, métodos de pesquisa, teorias organizacionais, demais perspectivas teóricas empregadas, características de autoria e medidas de redes sociais nos estudos de contabilidade gerencial publicadas no período de 2001 a 2018 em dez importantes revistas internacionais de contabilidade. Adicionalmente, buscou-se comparar os resultados com o estudo Hesford et al. (2007), pela atualização de dezoito anos posteriores de pesquisa, com o intuito de traçar tendências de publicações.

Frente aos principais resultados observados, infere-se que as características dos estudos analisados e que servem como norteamento para as pesquisas futuras referem-se a análise dos temas avaliação de desempenho (controle), sistema de controle gerencial (outros temas) e alocação de custos (custos). Entretanto, no que se refere a alocação de custos, constatou-se a ênfase em estudos sobre a assimetria de custos, em detrimento a alocação de custos por meio de sistemas.

Quanto aos métodos utilizados, observou-se maior ênfase naqueles que conseguem captar o mais próximo da realidade das empresas, como questionário, entrevista, estudo de caso e ou experimento. Infere-se desta forma, que os estudos vêm a contribuir com a linha positiva da contabilidade, por demonstrar como os fatos ocorrem dentro das organizações, com o intuito de explicar alguns fenômenos contábeis e prever às demais empresas. Observou-se que quando o pesquisador não se utiliza de métodos para captar a realidade das empresas, uma alternativa seria a utilização do método experimento, que vem a somar nas pesquisas, por possibilitar a criação de um cenário controlado semelhante ao vivido pelas organizações.

As teorias mais empregadas continuam sendo as econômicas, devido à consolidação de suas prescrições na área contábil, todavia, observou-se também que os principais pesquisadores do mundo e as principais revistas estão aderentes a outras teorias, como psicológicas, sociológicas e até mesmo filosóficas e físicas. Estas teorias de outras áreas estão sendo aos poucos inseridas na área contábil com o intuito de contribuir com diferentes explicações aos atos e fatos contábeis, uma vez que a contabilidade como um todo, é uma ciência social, em que possui impacto em diferentes contextos, sejam na sociedade ou indivíduos e necessita de elementos das teorias psicológicas e sociológicas, por exemplo, para expandir a sua explicação como ciência social.

Observou-se ainda, que há margem para o desenvolvimento da contabilidade gerencial tendo como alternativas pesquisas sendo 
realizadas por grupos, e que estes se mantenham atuantes ao longo do tempo, visto que a maioria dos estudos é realizada por autores que publicam somente uma única vez. Desta forma, infere-se a necessidade de fortalecimento dos grupos de pesquisa e da criação de mecanismos que os estimulem para que sejam compostos por pesquisadores de diferentes instituições e que contemplem participantes de múltiplas áreas de conhecimento.

Conforme o exposto se observou perspectivas futuras para as pesquisas em contabilidade gerencial. As perspectivas foram apresentaras conforme as abordagens de temas de pesquisa, o método e a teoria e indicam a direção para onde as pesquisas em contabilidade gerencial parecem estar se direcionando.

O escopo desta pesquisa limitou-se a analisar os principais periódicos internacionais, no entanto, a mesma pesquisa pode ser aplicada no cenário nacional. Nesse sentido, novos estudos podem comparar os principais periódicos brasileiros, americanos e europeus. Além disso, sugere-se a realização de estudos para verificar os motivos pelos quais ocorrem as redes de cooperação entre os autores, bem como, as parcerias realizadas com as instituições dos autores que estão realizando a interligação. Também poderia ser verificada a frequência e a ligação de diferentes países. 


\section{REFERÊNCIAS}

BROMWICH, M. The case for strategic management accounting: the role of accounting information for strategy in competitive markets. Accounting, Organizations and Society, v. I5, n. I-2, p. 27-46, 1990. BROWN, L. D.; GARDNER, J. C. Applying citation analysis to evaluate the research contributions of accounting faculty and doctoral programs. Accounting Review, p. 262-277, 1985.

COLAUTO, R. D.; BEUREN, I. M. Coleta, Análise e Interpretação dos Dados. Beuren, I. M. Como elaborar trabalhos monográficos em contabilidade: teoria e prática. $3^{\mathrm{a}}$ Ed. São Paulo: Editora Atlas S.A, 2012.

COOPER, D. Tidiness, muddle and things: commonalities and divergencies in two approaches to management accounting research. Accounting, organizations and Society, v. 8, n. 2-3, p. 269-286, 1983. COVALESKI, M.A.; DIRSMITH, M.W.; SAMUEL, S. Managerial accounting research: the contributions of organizational and sociological theories. Journal of Management Accounting Research, v. 8, n.I, 1996.

GUERREIRO, R., FREZATTI, F. \& CASADO, T. Em busca de um melhor entendimento da contabilidade gerencial através da integração de conceitos da psicologia, cultura organizacional e teoria institucional. Revista Contabilidade \& Finanças, v. 17, p. 7-2I, 2006.

HESFORD, J.W.; SAM LEE, S. H.;VAN DER STEDE, W. A.; YOUNG, S. $M$. Management accounting: a bibliographic study. En: Chapman, C.S.; Hopwood,A.G.; Shields, M.D.
Handbook of management accounting research, 2007.

HOPWOOD,A. G. Towards an organizational perspective for the study of accounting and information systems. Accounting, Organizations and Society, v. 3, n. I, p. 3-13, 1978. IUDÍCIBUS, S.; MARTINS, E.; CARVALHO, L. N. Contabilidade: aspectos relevantes da epopéia de sua evolução. Revista Contabilidade \& Finanças, v. 16, n. 38, p. 7-19, 2005.

KAPLAN, R. S. The role for empirical research in management accounting. Accounting, Organizations and Society, v. II, n. 4-5, p. 429452, 1986.

LEITE FILHO, G. A. Padrões de produtividade de autores em periódicos e congressos na área de contabilidade no Brasil: um estudo bibliométrico. Revista de Administração Contemporânea, v. 12, n. 2, p. 533-554, 2008.

MCRAE, T.W. A citational analysis of the accounting information network. Journal of Accounting Research, p. 80-92, 1974.

MURCIA, F. D.; BORBA, J. A. Possibilidade de Inserção da Pesquisa Contábil Brasileira no Cenário Internacional: Uma proposta de Avaliação dos Periódicos Científicos de Contabilidade e Auditoria publicados em Língua Inglesa e disponibilizados no Portal de Periódicos da CAPES. Revista Contabilidade \& Finanças, v. 46, p. 30-43, 2008.

NEIVA, E. R.; CORRADI,A.A.A psicologia organizacional e do trabalho no Brasil: uma análise a partir das redes sociais de pesquisadores da pós-graduação. Revista Psicologia
Organizações e Trabalho, v. 10, n. 2, p. 67-84, 2010.

OLIVEIRA, M. C. Análise dos periódicos brasileiros de contabilidade. Revista Contabilidade \& Finanças, v. I3, n. 29, p. 68-86, 2002.

PIGATTO, J. A. M; HOLANDA, V. B.; MOREIRA, C. R.; CARVALHO, F. A.A importância da contabilidade de competência para a informação de custos governamentais. Revista de Administração Pública, v. 44, n. 4, p. 82I-837, 2010.

SILVA, M. Z; BEUREN, I. M. Contabilidade gerencial em hospitais: análise bibliométrica de artigos publicados no período 1950 a 201 I. Revista Alcance (Online), v. 22, n. I, p. 80, 2015.

SOUZA, M.A.; LISBOA, L. P.; ROCHA, W. Práticas de contabilidade gerencial adotadas por subsidiárias brasileiras de empresas multinacionais. Revista Contabilidade \& Finanças, v. I4, n. 32, p. 40-57, 2003.

VAN DER STEDE,W.A.;YOUNG, S. M.; CHEN, C. X. Doing management accounting survey research. Handbooks of management accounting research, v. I, p. 445-478, 2006.

VANZ, S. A. S.; STUMPF, I. R. C. Procedimentos e ferramentas aplicados aos estudos bibliométricos. Informação \& Sociedade, v. 20, n. 2, 2010.

ZUCCOLOTTO, R., SILVA, G. M.; EMMENDOERFER, M. L. Limitações e possibilidades de compreensão da utilização das práticas de contabilidade gerencial por perspectivas da teoria institucional. BASE-Revista de Administração e Contabilidade da Unisinos, v. 7, n.3, p. 233-246, 2010. 